\title{
Automobilismo carioca: memórias de um piloto e as corridas de rua de 1954 a 1966
}

\author{
Rodrigo Vilela Elias* \\ Ludmila Mourão**
}

\begin{abstract}
Resumo: Esta pesquisa trata do desenvolvimento do automobilismo e suas relações com o crescimento urbano do Rio de Janeiro no período entre 1954 e 1966, abrangendo o fim do Circuito da Gávea e a construção do Autódromo. A história oral e a literatura sobre o esporte ajudaram a esclarecer transformações relacionadas ao envolvimento do automobilismo com a política, a recém-chegada indústria automobilística, a popularização do automóvel e as transformações sociais e urbanas. Os resultados apontaram para um sentido de desenvolvimento conturbado, alocado entre a prosperidade nacional e a má administração do automobilismo carioca, marcado por ações imediatas, improvisadas e privadas.
\end{abstract}

Palavras-chave: Automobilismo. Esporte. Indústria. Política.

\section{INTRODUÇÃo}

Esta pesquisa trata do desenvolvimento do automobilismo e suas relações com o crescimento urbano da cidade do Rio de Janeiro no período compreendido entre 1954 e 1966. Estão inseridos neste período fatos relevantes como o fim das corridas do Circuito da Gávea e o início da industrialização nacional, com foco para a indústria automobilística e a construção do Autódromo do Rio de Janeiro. Buscamos compreender este cenário histórico tendo como referência a importância do Circuito da Gávea para o automobilismo, para a cidade e suas relações políticas.Considera-se também a relevante transformação que a indústria automobilística proporcionou ao automobilismo e à sociedade em geral, que sentia mais próxima a possibilidade de aquisição do automóvel.

\footnotetext{
*Mestrando em Educação Física, Programa de Pós-Graduação da Universidade Gama Filho. Bolsista do CNPq. Rio de Janeiro, RJ. Brasil.. E-mail: rodrigovilelaelias@gmail.com.

** Professora da Universidade Gama Filho no curso de Graduação e no Programa de PósGraduação em Educação Física, Rio de Janeiro, RJ. Brasil. E-mail: Ludmila.mourao@terra.com.br.
} 
O objetivo deste trabalho é descrever as relações entre automobilismo e a cidade do Rio de Janeiro, levando em consideração as transformações urbanas e as modificações políticas, sociais e econômicas do Brasil. Para tanto, entrevistamos o ex-piloto Amaury Mesquita, que construiu sua carreira nas décadas de 1960 e 1970, correndo de kart e carros de corrida em diversas categorias e pistas do Rio de Janeiro, vivenciando, portanto, as questões envolvidas neste estudo. Paralelamente, buscamos complementar, comparar e agregar, aos fatos narrados pelo entrevistado, informações obtidas através de uma revisão da literatura. A história oral permite encontrar evidências mais penetrantes e fundamentais, contribuindo para uma história mais rica, viva, comovente e verdadeira (THOMPSON, 1992); entretanto, sabe-se da sua subjetividade, passível de falhas e fantasias, por isso a importância de comparação com outras fontes para ampliar a confiabilidade sobre os dados colhidos.

\section{CONTEXTO INDUSTRIAL NACIONAL}

Embora a quantidade de carros que circulava nos grandes centros urbanos brasileiros, nos anos 1950, fosse considerável, boa parte da população não tinha acesso ao automóvel. Foi preciso nacionalizar este produto para que o país se desenvolvesse sobre rodas e estradas.

Durante o segundo Governo Vargas, de 1950 a 1954, houve uma tentativa de trazer a indústria automobilística para o Brasil, que não deu certo face às dificuldades que as fábricas teriam para se instalar, devido ao alto custo de importação do maquinário, pouca mão-de-obra qualificada, pequena quantidade de matéria-prima e pequeno parque industrial (VILELA, 2006).

O Governo Vargas começou a criar meios para mudar esse quadro em 1953, quando proibiu a importação de peças de reposição e, logo em seguida, de carros inteiros, levando a Volkswagen, a Mercedes e a Willys Overland a se instalarem no país. A criação da A criação da CSN (Companhia Siderúrgica Nacional) em 1946 e da Petrobras em 1953 aumentou gradualmente a autonomia nacional 
na produção de petróleo e metais, o que era vital para a implantação do setor automotivo no país (VILELA, 2006).

Em 1956, já no Governo de Juscelino Kubitschek e de acordo com as intenções do "Plano de Metas" para o desenvolvimento nacional, ocorre a implantação da indústria automobilística em São Bernardo do Campo, São Paulo. Não só o carro familiar chegava, mas veículos comerciais também começavam a proliferar, e uma maior estrutura de estradas para comportá-los fazia-se necessária.

O "Plano de Metas" foi responsável pela configuração do modelo de desenvolvimento industrial que o Brasil adotaria. A penetração do capital estrangeiro ocorreu de forma maciça e ocupou os ramos pesados da indústria nacional, incluindo a indústria automobilística, de material elétrico, eletrônico e eletrodoméstico, produtos químicos, farmacêuticos e matéria plástica. Ainda de acordo com este plano, o capital estatal ficou encarregado de viabilizar o programa de infraestrutura destinado a sustentar o modelo através da construção de rodovias e da ampliação do potencial de geração, transmissão e distribuição de energia elétrica (KOSHIBA; PEREIRA, 1996).

Nas décadas de 1950 e 1960, a confiança do povo brasileiro de que o país caminhava em direção ao Primeiro Mundo era grande. $\mathrm{O}$ desenvolvimento das metrópoles nacionais, a estabilidade econômica e política e o desenvolvimento industrial eram motivos mais do que suficientes para essa confiança creditada ao Brasil. Num período de 50 anos, e mais intensamente dos anos 1950 ao fim da década de 1970, construímos uma economia moderna, com padrões de consumo comparado aos países desenvolvidos. Fabricávamos aços especiais na CSN, Cosipa, Usiminas e outras. Da Petrobras saíam o petróleo e seus derivados. Nossa engenharia havia erguido Furnas e Itaipu, hidroelétricas gigantescas, equipadas com geradores e turbinas nacionais (MELLO; NOVAIS, 1998).

O desenvolvimento brasileiro localizado na urbe provocou um êxodo rural. Homens e mulheres do campo chegavam às grandes cidades de trem, ônibus, jipe, caminhão ou automóvel, na esperança de uma vida menos sofrida, com melhores oportunidades e um 
futuro mais digno para os filhos, que agora poderiam frequentar escolas e alcançar um emprego melhor que o dos pais.

O "Plano de Metas" adotado por Juscelino Kubitschek foi um dos potencializadores desses acontecimentos. No fim dos anos 1950 havia 11 indústrias somente na área automobilística, além de 1.200 empresas de autopeças, com 105 mil empregados. (MELLO; NOVAIS, 1998). Os empregados dessas fábricas, mecânicos, comerciantes de autopeças, lanterneiros e pintores, seriam justamente esses migrantes e imigrantes que viam seu próprio sucesso na prosperidade nacional, urbana e industrial.

O surgimento do setor automotivo nacional facilitou o acesso ao carro para camadas da população que antes não podiam importar um automóvel, o que provocou transformações urbanas, econômicas e políticas As cidades se adaptavam ao automóvel com a construção de viadutos, pontes e túneis; os bondes eram substituídos pelos ônibus, e uma nova elite urbana e industrial se formava, com novos interesses e poderes, fazendo frente à antiga elite do café com leite. $\mathrm{O}$ automobilismo também sofreu influências, já que os carros de corrida da época, e até hoje na maioria das categorias, são carros de uso comum transformados para obter melhor desempenho.

A demanda pelo automóvel era grande e surgia um mercado com diversos produtos automotivos no seu entorno; entretanto, investimentos ainda deveriam ser feitos. Os carros e todo tipo de produto relacionado precisavam ser melhorados e necessitavam de uma vitrine para divulgação.

Isto ocorria em função da fragilidade que os carros apresentavam, exigindo uma manutenção muito maior do que a que ocorre atualmente. Sendo assim, a busca pelo desenvolvimento de peças que tornassem os carros mais confiáveis e resistentes era uma das intenções das fábricas, naquele tempo.

O investimento das indústrias no automobilismo foi grande, fábricas recém-instaladas no país criaram equipes de corrida, e rapidamente o Autódromo de Interlagos, em São Paulo, e as diversas 
corridas que se realizavam pelo Brasil se transformaram em laboratórios e grande meio de propaganda.

Todos os testes que seriam feitos em estradas em condições normais de uso foram acelerados através das corridas, utilizando os carros e produtos no limite do desgaste. Pneus, rodas, motores e todo tipo de partes mecânicas foram aperfeiçoados, e essas evoluções transferidas aos carros vendidos para o público em geral. As vitórias eram estampadas nos anúncios de revistas, e modelos esportivos de carros surgiam, assim como diversos acessórios baseados nas corridas. Os pilotos tinham seu papel, eram os garotos propaganda e ídolos de uma geração. Apareciam nos jornais, revistas e rádio, em reportagens sobre as corridas e em anúncios dos carros que utilizavam nas corridas.

O automobilismo se tornou atração e o modelo esportivo propagado pelo esporte era rapidamente absorvido pela sociedade. Os produtos que remetiam a esse modelo como: rodas, volantes esportivos e faixas decorativas se popularizavam, assim como os modelos de carros esportivos, como: Willys Interlagos e DKW Malzoni.

\section{CIRCUITO da GávEA, OUTRAS CORRIDAS E O AUTÓDROMO do RIO DE JANEIRO}

Na primeira metade do século XX o Circuito da Gávea foi um evento automobilístico de grande expressão no Brasil, apresentando inclusive relevância internacional (VILELA, 2010). Este Circuito aconteceu de 1933 até 1954, com um pequeno intervalo entre os anos de 1942 a 1946, devido à Segunda Grande Guerra. Pilotos estrangeiros e equipes internacionais se deslocavam para o Brasil a fim de participar do evento. O Circuito era de grande magnitude, toda a cidade via-se envolvida com o acontecimento, que chegava a atrair 250 mil espectadores para assistir máquinas velozes e pilotos corajosos correndo pelas ruas dos bairros da Gávea e do Leblon, na Zona Sul da cidade do Rio de Janeiro (DELAMARE; TEIXEIRA; MAIA, 2005). 
O Circuito da Gávea se inseria no período político relacionado ao primeiro Governo de Getúlio Vargas: a primeira corrida aconteceu em 1933 e as provas de 1937 a 1941 ocorreram durante o Estado Novo. O circuito propagava os interesses políticos e econômicos do país, que visava a implantação de um parque industrial nacional; além disso, atendia a uma política de Estado cujo interesse era integrálo no projeto de construção de uma identidade nacional (MELO, 2008).

Não por acaso, mas em função da importância que a corrida atingiu, as influências geopolíticas foram marcantes. Em 1933 o presidente da Itália, Mussolini, encaminhou um telegrama ao Barão Manuel de Teffé, vencedor da corrida, dizendo o quanto se sentia envaidecido pela vitória intercontinental de um carro italiano - no caso, um Alfa Romeo, e em 1937, houve a presença de uma equipe alemã durante o regime nazista (MELO, 2008).

Em vista da posição de destaque que atingiu no calendário automobilístico, a corrida do Circuito da Gávea mantinha o Rio de Janeiro como centro do automobilismo no país. Nesta época, precisamente em 1940, foi construído o Autódromo de Interlagos, em São Paulo, que, mesmo se constituindo como o local adequado para a prática do automobilismo, suas corridas não conseguiam fazer frente à importância do Circuito da Gávea.

No segundo Governo de Vargas tivemos importantes edições da corrida: em 1952, a presença do famoso piloto argentino Juan Manuel Fangio movimentou a corrida, e no último ano de sua realização,em 1954, foi preparada uma surpresa para o maior piloto e ídolo brasileiro na época, Chico Landi, com a compra de uma Ferrari para que ele disputasse a prova. Chico Landi negou a participação de Vargas na compra da Ferrari; dizia detestar política, entretanto, não negava sua proximidade com o presidente (MELO, 2008).

A partir desta época, ou seja, metade final da década de 1950, o automobilismo no Rio de Janeiro perde prestígio. Terminam as corridas do Circuito da Gávea, que teve sua última edição em 1954, 
mesmo ano da morte de Vargas, confirmando a forte ligação e influência do presidente com a realização da prova. Nesta prova, os acidentes e as dificuldades da pista, levaram a corrida a ficar conhecida como "Trampolim do Diabo". Aliado a isso, o povoamento da Zona Sul do Rio de Janeiro aumentava ainda mais o perigo da prova, cuja continuidade se devia apenas a vontade política de Vargas, que passava por cima de tudo e decidia pela realização da corrida.

Em 1956 há a implantação da indústria automobilística em São Paulo, fortalecendo o estado vizinho. A união dessas indústrias com o Autódromo de Interlagos facilitou a logística de acesso a carros e peças, transformando-o no local ideal para a realização de corridas. A corrida Mil Milhas Brasileiras, com sua primeira edição em 1956, substituiu o Circuito da Gávea como a maior corrida do calendário nacional. Em Interlagos aconteciam diversas provas, a maioria delas longas, como a Mil Milhas, os $500 \mathrm{~km}$ de Interlagos, entre outras. Corridas deste tipo já eram comuns nesta época não só no Brasil, mas em outros países. Um exemplo é a lendária 24 Horas de Le Mans, na França, e as 500 Milhas de Indianápolis, nos EUA. Apesar de copiarmos o estilo de corrida internacional, percebe-se que, esse fato ajudou a desenvolver a indústria automobilística nacional, pois quanto mais quilômetros rodados nas pistas, mais peças e carros eram testados e mais rapidamente nossa indústria evoluía.

Em 1960 o Rio de Janeiro deixou de ser a capital do país, e neste pequeno espaço de tempo (1954-1960) percebe-se a perda da sua força política e um fortalecimento econômico de São Paulo que acabou se tornando o centro do automobilismo no Brasil. Como no Rio de Janeiro não havia um autódromo, as corridas, devido ao grande crescimento urbano, foram obrigadas a se adaptar as novas formas urbanas da metrópole. Com isso as provas deveriam acontecer impactando menos no traçado urbano, ou em locais mais adequados, longe do já complicado trânsito das áreas centrais da cidade.

$\mathrm{Na}$ Zona Sul, o status da vida a beira-mar, difundido pelas empresas da construção civil, atraía a população rica. É a partir desta época que o bairro de Copacabana sofre o processo de verticalização. Um processo que foi tão marcante e lucrativo para as empresas que 
mesmo a abertura da Avenida Presidente Vargas, oferecendo terrenos para a construção de edifícios modernos, não atraiu a construção civil. Não só a Zona Sul mas, a cidade como um todo crescia, alguns bairros da Zona Norte, como São Cristovão, se notabilizaram pelo surgimento de um grande número de indústrias (ABREU, 2008).

Entretanto, a estrutura da cidade não estava acompanhando este crescimento. A malha viária, transporte, energia elétrica, telefonia, água, saneamento e habitação apresentavam problemas. A cidade, conturbada e inchada, precisava de uma reforma que a equilibrasse e a preparasse para o futuro. A época de glamour dos anos 1950 contrastava com as debilidades e problemas.

Somente na gestão de Negrão de Lima (1956 a 1958), com a criação do Fundo especial de Obras Públicas e da Superintendência de Urbanismo e Saneamento (Sursan) foi dado um impulso para superar alguns problemas, adiantar e terminar algumas obras necessárias para a cidade. Com essa medida, foram construídas 78 escolas, o túnel Barata Ribeiro-Raul Pompéia (em Copacabana), concluído o Elevado da Perimetral (ligando a Zona Sul ao Centro) e inaugurada a Avenida Chile (no Centro) com a conclusão do desmonte do Morro de Santo Antonio. No bairro da Barra da Tijuca, para realização de eventos automobilísticos, houve a pavimentação de ruas e retificação de curvas. Outras obras continuaram inacabadas, como a construção do Túnel Santa Bárbara (PEREZ, 2007).

Mesmo com essas obras, para Carlos Lacerda, eleito governador em outubro de 1960, o carioca estava insatisfeito por viver numa cidade suja, desorganizada e sem dinamismo. Tudo estava indo ao contrário da modernidade pregada desde o início do século na Reforma Passos. Havia falta de água, assim como de escolas e assistência médica. A cidade não andava, o trânsito era caótico, e depois de mais de meio século a Avenida Beira-Mar não dava mais conta da quantidade de automóveis e ônibus que havia na cidade. Eram necessárias duas horas de carro para se chegar ao centro, (PEREZ, 2007).

No governo de Lacerda (1960 a 1965) os resultados alcan- 
çados foram os seguintes: construção de cerca de duzentas escolas primárias, correspondendo a $65 \%$ das escolas existentes até então; crescimento em 30\% da rede hospitalar; edificação de cerca de 12 mil casas populares que receberam os moradores de favelas removidas, como a Favela do Esqueleto na região do Maracanã e Favela do Pinto, no bairro do Leblon; abertura da adutora do Guandu, que exigiu a perfuração de um túnel na rocha com 43 quilômetros de extensão e permitiu a expansão da rede de água em 900 quilômetros; a instalação de 600 quilômetros de esgoto; inauguração de 19 viadutos; perfuração de 5,6 quilômetros de túneis; remoção dos bondes e introdução de 600 novos ônibus; instalação de três usinas de coleta de lixo e a entrega do Parque do Flamengo (PEREZ, 2007).

Mas, acima de tudo, a cidade tinha que se adaptar, mais uma vez aos automóveis.

Por outro lado, também não há como negar que uma revolução estava ocorrendo por conta da expansão do automóvel, uma revolução que punha em xeque a cidade: ou ela se ajustava a essa realidade ou pararia. De 1957 a 1964, o numero de veículos de passageiros no estado passou de 63 mil para 140 mil, um aumento de mais de $100 \%$ em apenas oito anos (PEREZ, 2007, p. 227).

A cidade passou a contar, enfim, com as qualidades de uma cidade cosmopolita que agora se baseava no modelo norte-americano, no trânsito livre dos automóveis, e compatível com os grandes investimentos nacionais feitos na indústria automobilística. Se Brasília era a "Nova Cap." o Rio de Janeiro era a "Bela Cap." mais uma vez, apresentando o dinamismo de uma cidade moderna. (VILELA, 2010).

A partir dessas mudanças e problemas porque a cidade passou entende-se como era complicado organizar uma corrida de automóveis por suas ruas. De 1954 até 1966, período que se segue à realização da última corrida do Circuito da Gávea até a construção do Autódromo do Rio de Janeiro, tem-se um período de sombra no automobilismo carioca, provocado pela perda de prestígio com o fim do Circuito da Gávea, e agravado pelas mudanças urbanas e pela 
má administração do esporte feita pelo Automóvel Club do Brasil (ACB). Era cobrado do ACB, melhor organização e maior quantidade de corridas na cidade além de maior aproximação das indústrias automobilísticas.

Nesse período as corrida passaram a ocupar diferentes localidades da cidade como: a região do Castelo, praia de Botafogo e região do Maracanã, áreas bastante povoadas, e inadequadas à realização de corridas. Em seguida, no fim dos anos 1950, as corridas foram transferidas para a Barra da Tijuca, um bairro distante e pouco povoado, o que facilitava a organização dos eventos automobilísticos. Inicialmente estas corridas foram bem sucedidas e pareciam fazer emergir o esporte na cidade do Rio de Janeiro. Contudo, houve problemas com a cobrança de ingressos em duas corridas no ano de 1960. O acesso à Barra nessa época se fazia somente por uma ponte, onde ficava a bilheteria; mas como os preços eram muito altos, os barqueiros da região aproveitaram a oportunidade para transportar as pessoas por um preço mais baixo, o que prejudicou a viabilidade financeira do evento (GONÇALVES, 1999). Além disso, foi alegado pela prefeitura que as corridas atrapalhavam o acesso de banhistas à praia e as provas tiveram sua realização proibida.

Mesmo tendo sido capital federal e sendo sede do Automóvel Clube do Brasil, a falta de um autódromo atrapalhava o desenvolvimento do esporte. A Revista de Automóveis (O AUTÓDROMO..., 1954) publicou matéria sobre o projeto de um autódromo que seria construído em Adrianópolis, pequena cidade da Baixada Fluminense às margens da atual Rodovia Presidente Dutra. Uma década depois, a revista Quatro Rodas (ADRIANÓPOLIS..., 1964) trouxe a notícia de que o terreno chegou a sofrer terraplanagem, mas o projeto nunca saiu do papel.

No início dos anos 1960 as corridas voltam a ocorrer no centro urbano com provas no Aterro da Glória e na região do Maracanã. Mais uma vez as provas apresentam dificuldades de organização e uma pista pobre tecnicamente, sem grandes atrativos para os pilotos (VILELA, 2010). Contudo o público se mostrava interessado e comparecia aos locais dos eventos. Os espectadores se amontoavam 
nas calçadas, arriscando-se a escapada de um carro para assistir as corridas. A única barreira que existia entre o público e a pista de corridas eram blocos de feno, insuficientes para conter um automóvel em alta velocidade

As influências deste novo esporte ganhavam força entre os jovens, o que levava à realização de corridas clandestinas, os famosos "pegas de rua" ou "rachas". Na revista Quatro Rodas uma reportagem intitulada "Ventanias no volante" (VENTANIAS...,1964) falava sobre essas corridas, relatando que os jovens corriam pelas ruas da Zona Sul do Rio de Janeiro com total imprudência, transitando na contramão e acelerando seus carros a mais de $100 \mathrm{~km}$ por hora. Os jovens se encontravam num posto de gasolina na Avenida Vieira Souto, em Ipanema, conversavam sobre seus carros, combinavam as corridas e dali saiam acelerando.

No final de 1964 as corridas voltam a acontecer na Barra da Tijuca confirmando a maior adequação do local para realização de provas do que em outras áreas da cidade. Mesmo com problemas para cobrança de ingressos, a organização no local era melhor, pois quase não havia impacto na dinâmica da cidade. Era melhor prejudicar o acesso a praia para alguns banhistas, do que desorganizar o centro urbano. Outro ponto positivo era o traçado da pista de corridas que, considerado melhor e mais técnico, atraía os pilotos e elevava o número de corredores. Em consequência, a maior qualidade técnica da prova atraía o público que comparecia em massa (VILELA, 2010). A popularização das corridas deixou claro como se tornou intensa a relação entre a população e o carro. Percebe-se que, mesmo o automóvel apresentando mais de meio século de existência no Brasil, somente se tornou popular com a implantação da indústria em 1956.

Acredita-se que foi o contexto de desenvolvimento nacional, com mudanças sociais e políticas, aliado ao interesse de uma parcela da população pelas corridas e o grande investimento das indústrias no automobilismo, que motivou a construção de um local específico para a realização de corridas no Rio de Janeiro. 


\section{As NARRATIVAS DO PILOTO}

Para este estudo, entrevistamos o ex-piloto das décadas de 1960 e 1970, Amaury Mesquita, que testemunhou parte dos fatos aqui apresentados. Ele nos conta que, ainda na época do bonde, aprendeu a dirigir com seu pai e acabou criando gosto pelo automóvel. Na década de 1950, quando assistiu a sua primeira corrida, teve a certeza de que algum dia se tornaria um piloto. Como ele mesmo disse: "Não morro sem correr de automóvel".

Pela facilidade de acesso às corridas que aconteciam pelos bairros da cidade do Rio de Janeiro, era mesmo de se esperar que os jovens fossem influenciados a iniciar suas carreiras no automobilismo.

O início da carreira de piloto de Amaury foi com o Kart, uma categoria difundida no Brasil pelos irmãos Emerson e Wilson Fittipaldi, na década de 1960. Os pequenos carros de corrida eram baratos e de fácil manutenção, qualidades ideais para que qualquer interessado por corridas começasse a praticar.

Segundo Amaury:

O início da carreira no automobilismo foi junto com 40 kartistas que construíram a primeira pista de Kart no Rio de Janeiro, em 1963, do próprio bolso, localizada no Motel Country Clube Bandeirantes, lá no final da Avenida das Américas, onde hoje existe um Camping Clube.

A construção da pista de Kart da Barra da Tijuca seguiu o deslocamento das corridas de rua para o distante bairro. Essas modificações nos locais de realização de provas revelaram como a cidade aos poucos empurrou estes eventos do centro urbano para a periferia. A realização de provas neste bairro apontou o sentido de crescimento urbano do Rio de Janeiro, que durante as obras do governo Lacerda (1960-1965) foi afirmado com a criação do plano diretor para ocupação da Barra Tijuca, pelo arquiteto Lucio Costa.

Amaury participou também das corridas de Quilômetro de Arrancada que aconteciam próximo da sua casa. Ele morava em Vila 
Isabel e as corridas aconteciam na Avenida Radial Oeste, nos arredores do Maracanã. A região do estádio se constituía com um espaço de identidade esportiva do Rio de Janeiro, um local que se reorganizava, já que o Maracanã foi construído onde antes havia um estádio de Turfe; e a avenida citada havia sido aberta há pouco, como uma das diversas obras que aconteceram na cidade para melhorar sua dinâmica viária. As corridas nesse caso se aproveitaram destes espaços reorganizados para o trânsito do automóvel.

No ano de 1963, na modalidade Subida de Montanha, que se constituía como um deslocamento das corridas do centro urbano para locais que proporcionassem menor impacto urbano, Amaury foi o primeiro colocado: "Foram três provas de Arrancada, ato contínuo Subida de Montanha, [...] e sou o primeiro colocado".

A sequência da carreira na subida de Furnas, no Alto da Boa Vista, foi o marco de segurança e auto-estima que o piloto precisava para continuar correndo. Subidas de Montanha são corridas difíceis, exigem do carro um esforço enorme para superar ladeiras, e o piloto precisa apresentar habilidade e coragem para controlar o carro. Para Amaury, a exigência era dupla: além de apresentar habilidades como piloto ele também devia ser bom mecânico, pois não possuía uma equipe com grande estrutura - pelo contrário, sua equipe era constituída por ele e um mecânico amigo.

Nunca ninguém sentou ao meu lado para dar uma volta e dizer: é assim que se faz... assim... assado, se toma (curva) assim, se freia assim. [...] Isso ai tudo de mexida de Vemag (DKW), é tudo ideia minha. Esse rapaz que me ajudava, você vê que coincidência, o sobrenome dele era Ferrari. Luiz Carlos Ferrari de Sá.

O carro utilizado por Amaury era um DKW Vemag Sedan ${ }^{1}$, uma das maravilhas que nossa recente indústria produzia e que foi difundido pelas corridas. O departamento de corridas da DKW era famoso, e foram muitas as vitórias que os carros transformados para corridas alcançaram.

1Disponível em: <http://www.bandeiraquadriculada.com.br/Amauri\%20Mesquita.htm>. Acesso em: 23 mar. 2009. 
Nesta época os patrocínios não existiam, assim como pilotos profissionais. O mais comum eram as permutas, ou seja, algum fabricante fornecia peças em troca de espaço para divulgação no carro. $\mathrm{Na}$ maioria das vezes, eram os pilotos que investiam verba do próprio bolso ou contavam com a ajuda da família.

Somente com o investimento que as fábricas faziam esse quadro começou a mudar, de forma lenta. Primeiro os pilotos de ponta corriam sem receber e sem pagar nada, em seguida começaram a receber salários e carros das fábricas que representavam nas corridas. No Rio de Janeiro essa situação era agravada pela distância das fábricas e pela falta de um autódromo. Assim como muitos outros, Amaury não teve patrocínio em sua carreira.

[...] ou existia o patrocínio do pai, ou então era do próprio bolso. No meu caso específico, era do meu próprio bolso. [...] a Vemag foi a primeira equipe profissional no Brasil. O Bird (Clemente) foi o primeiro piloto a receber salário, todos os outros até então não ganhavam nada. Não pagavam nada mas não ganhava nada, ficava empatado.

A partir deste ponto, as corridas são inúmeras, tanto no Rio de Janeiro como em São Paulo. Barra da Tijuca, Ilha do Fundão e Interlagos eram traçados conhecidos do piloto. Entretanto, alguns acontecimentos revelam uma realidade triste no Brasil. O ACB (Automóvel Club do Brasil), organizador das corridas, não facilitava a vida dos pilotos e não cumpria seu papel de fomentador do esporte, tanto que nos anos 1960 uma longa briga levou à criação da CBA (Confederação Brasileira de Automobilismo). Nas palavras do expiloto, "Aqui no Rio, quem organizava corrida era o Automóvel Clube do Brasil, ali houve uma série de falcatruas, [...] que levaram àquela situação". Sobre as causas de fundação da CBA e os problemas do ACB, a resposta foi direta, "[...] para ver se moralizava. [...] O que é que tinha no ACB? [...] Corrupção".

Nesta época, em virtude das dificuldades que o ACB apresentava para a realização das corridas e a pouca movimentação dos seus dirigentes, surge um grupo de pessoas ligadas ao automobilismo buscando mudanças para o esporte. Um dos líderes desse 
movimento foi Wilson Fittipaldi, pai do nosso piloto campeão mundial de Fórmula 1, Emerson Fittipaldi. Como organizador de corridas, Wilson enfrentava muitas dificuldades. O presidente do ACB na época era o General Santa Rosa, que baixava regras e normas de forma autoritária. Para realizar qualquer evento automobilístico, era obrigatória a presença de um ou mais delegados do $\mathrm{ACB}$, com todas as despesas pagas; havia também outras taxas e exigências que dificultavam a realização de corridas (MARTINS, 2004). Outro ponto de discórdia era a proibição, por parte do $\mathrm{ACB}$, dos pilotos saírem do país para competir em categorias internacionais; havia sanções e punições para os que desrespeitavam as regras.

Além disto, também era preciso combater a dita "corrupção". Wilson Fittipaldi, que além de organizar corridas trabalhava como radialista, chegou a denunciar em seu programa de rádio um esquema de contrabando de automóveis que envolvia o Automóvel Clube do Brasil (MARTINS, 2004). O embate entre ACB e CBA durou de 1961 até 1969. O ponto central da briga era o reconhecimento do ACB pela Federação Internacional de Automobilismo, que a CBA não possuía e que a impedia de assumir o controle do esporte no Brasil.

O Rio de Janeiro não tinha a mesma quantidade de corridas que São Paulo, e muito menos o privilégio de estar próxima das fábricas de automóveis e peças em geral. Entretanto, as corridas não cessavam e a construção do autódromo se fazia imperativa. Em 1966 o Autódromo do Rio de Janeiro foi inaugurado, a obra feita pela iniciativa privada, ergueu a praça automobilística, em Jacarepaguá, (Bairro da Zona Oeste vizinho a Barra da Tijuca) seguindo o sentido de crescimento urbano do Rio de Janeiro, e que depois de passar por dificuldades de manutenção, passou a ser administrado pela prefeitura.

Matéria na revista Quatro Rodas (janeiro de 1966) apontava para a construção do melhor autódromo da América Latina, com estacionamento, grandes arquibancadas, restaurantes, lanchonetes e boxes grandes com toda infra-estrutura para pilotos e equipes Mas não foi exatamente isso que aconteceu. No local somente havia a 
pista com dois traçados diferentes para corridas, não havia estacionamentos, as arquibancadas e os boxes eram improvisados e o mato que envolvia a pista era alto. Imagens que eram claramente vistas nas fotos sobre as corridas inaugurais dos traçados externo e interno que a revista Quatro Rodas reportava, respectivamente em agosto e outubro de 1966.

Não era nada diferente daquilo com que os pilotos estavam acostumados, pois Interlagos também não oferecia estrutura. No traçado paulista os pilotos conviviam com buracos, já que desde a construção, em 1940, o asfalto era o mesmo. Na época em que o Autódromo do Rio de Janeiro foi inaugurado, o circuito paulista entrou em reformas para torná-lo adequado e seguro, dispondo de toda a estrutura de boxes necessária para receber eventos internacionais. Por três ou quatro anos a cidade do Rio de Janeiro foi mais uma vez o centro deste esporte. Nas palavras de Amaury;

A história daquele autódromo, aquele local era de propriedade da Predial Caledonia. Essa Predial Caledonia andou vendendo títulos de proprietário e tudo mais, de vagas cativas, só que ela se associou à construtora Iamakata e depois saiu do circuito, foi feito uma cadeia sucessória, aí aqueles que compraram títulos [...] se deram por perdidos. Até que a prefeitura encampou o autódromo, a Rio-Tur, principalmente. [...] Foi uma época inclusive que Interlagos estava sendo reformado e o automobilismo ficou todo no Rio de Janeiro, e aí foi um boom que as autoridades não conseguiram manter. Depois, quando o autódromo de Interlagos foi reinaugurado, a hegemonia do esporte passou para São Paulo.

Após a construção do Autódromo do Rio de Janeiro, todas as corridas passam a acontecer nesse espaço e os circuitos de rua na cidade chegam ao fim. 


\section{Considerações FINAIS}

Nesta pesquisa sobre o desenvolvimento do automobilismo e suas relações com o crescimento urbano da cidade do Rio de Janeiro encontramos modificações na organização deste esporte, bem como na movimentação dos atores envolvidos com esta prática, revelando uma história de altos e baixos.

Percebe-se que a realização do Circuito da Gávea na cidade do Rio de Janeiro esteve ligada à figura do Presidente Getulio Vargas, e a importância econômica do Estado de São Paulo, aliada à presença de um autódromo, soma as condições propícias para que a prática do esporte passasse a ocorrer num novo contexto de crescimento e industrialização nacional. A força política do Rio de Janeiro foi reduzida, culminando com a transferência da capital federal para Brasília. Como consequência, o automobilismo perde importância, passando a ser realizado em locais distantes, em detrimento da organização e crescimento urbano.

A falta de local adequado não deixava outra saída senão as corridas na rua. Os espectadores revelavam a excitação que o carro e as corridas apresentavam, pois neste momento grande parte da população passou a ter acesso ao automóvel e interesse pelo automobilismo. Mesmo a distância dos locais de corridas não impedia o público de comparecer.

Percebe-se com isso uma relação simbiótica que havia entre o automobilismo, as indústrias e o desenvolvimento nacional, onde ao mesmo tempo em que as pessoas se interessavam pelas corridas porque o carro nacional era uma novidade, elas se interessavam pelo carro nacional porque viam nas corridas tudo que ele podia fazer e o quanto eram evoluídos. Sentiam-se envaidecidas por fazerem parte do progresso nacional, e encontravam nas corridas os ídolos e os carros que passariam a fazer parte dos seus sonhos e projeto de vida. A emoção das corridas fomentava a necessidade do consumo e tornava brilhante a indústria e o desenvolvimento nacional.

Os caminhos percorridos pelo ex-piloto aqui entrevistado 
revelam o desenvolvimento conturbado do automobilismo no Rio de Janeiro: praticantes e espectadores viviam este esporte sob ações de caráter improvisado, dependendo muito mais dos apaixonados que investiam no automobilismo, e das indústrias que utilizavam as corridas em função de seus interesses comerciais, que da organização das entidades responsáveis.

Motorsport in Rio de Janeiro City: Driver
memories and street races between 1954 and
1966
Abstract: This research deals with motorsport
development and its relations with the urban growth
of Rio de Janeiro between 1954 and 1966, including
the end of the "Circuito da Gávea" and the construction
of the Speedway. The oral history and the literature of
the sport helped to clarify the changes related to the
involvement of the motorsport with politics, the arrival
of the automotive industry, the popularization of
automobile, and social and urban changes. The results
pointed to a sense of troubled development allocated
between national prosperity and bad administration of
motoring, which was marked by immediate, improvised
and private actions.
Keywords: Motorsport. Sport. Industry. Politics.

Automovilismo en la ciudad de Rio de Janeiro:
Las memorias de un piloto y las carreras en las
calles entre 1954 y 1966
Resúmen: Esta investigación se ocupa del desarrollo
del automovilismo y sus relaciones con el crecimiento
urbano del Rio de Janeiro desde 1954 hasta 1966,
marcando el final del "Circuito da Gávea" y la
construcción del Autódromo. La historia oral y la lite-
ratura del deporte ayudaron a aclarar cambios rela-
cionados con la participación del automovilismo en la
política, la llegada de la industria automotriz, la
popularización del automóvil y los cambios urbanos y
sociales. Los resultados apuntaron a un desarrollo
conturbado, con problemas asignados entre la
prosperidad nacional y la mala administración del de-
porte, en virtud de acciones inmediatas, improvisadas
y privadas.
Palabras clave: Automovilismo. Deporte. Industria.
Política.

Wovimento, Porto Alegre, v. 16, n. 03, p. 51-70, julho/setembro de 2010. 


\section{REFERÊNCIAS}

ABREU, Mauricio de A. A evolução urbana do Rio de Janeiro. 4. ed. Rio de Janeiro: Instituto Municipal de Urbanismo Pereira Passos, 2008.

ADRIANÓPOLIS: pista que virou maquete. Quatro-Rodas, São Paulo, v. 5, n. 45, p. 8, abr. 1964.

AUTÓDROMO Internacional do Rio. Quatro-Rodas, São Paulo, v. 6, n. 66, p. 171, jan. 1966.

CAROL ganha um lugar ao sol. Quatro-Rodas, São Paulo, v. 7, n. 73, p. 108, ago. 1966.

DELAMARE, Myriam; TEIXEIRA, Américo; MAIA, Breno. Automobilismo. In: DACOSTA, Lamartine (Org.). Atlas do esporte no Brasil. Rio de Janeiro: Shape, 2005. p. 375-379.

GONÇALVES, Ayrton Luiz. Barra da Tijuca: o lugar. Rio de Janeiro: Thex, 1999.

KOSHIBA, Luiz; PEREIRA; Denise M. F. Historia do Brasil. São Paulo: Atual, 1996.

MARTINS, Lemyr. A saga dos Fittipaldi. São Paulo: Panda, 2004.

MELO, Victor Andrade de. Antes de Fittipaldi, Piquet e Senna: o automobilismo no Brasil (1908-1954). Revista Brasileira de Ciências do Esporte, Rio de Janeiro, v. 30 , n. 1, 2008.

O AUTÓDROMO de Adrianópolis será o mais avançado do mundo! Revista de Automóveis, Rio de Janeiro, v. 1, n. 8, p. 23, ago. 1954.

MELLO, João Manuel Cardoso; NOVAIS, Fernando A. capitalismo tardio e sociabilidade moderna. In: SEVCENKO, Nicolau (Org.). A história da vida privada no Brasil: contrastes da intimidade contemporânea. São Paulo: Companhia das Letras, 1998. p. 559-658.

PEREZ, Maurício Dominguez. Lacerda na Guanabara: a reconstrução do Rio de Janeiro nos anos 1960. Rio de Janeiro: Odisséia, 2007.

Primeira briga caiu no Rio. Quatro Rodas, São Paulo, v. 7, n 75, p. 118, out. 1966. THOMPSON, Paul. A voz do passado: história oral. Rio de Janeiro: Paz e Terra, 1992.

VENTANIAS no volante. Quatro-Rodas, São Paulo, v. 5, n. 46, p. 108, maio 1964.

VILELA, Rodrigo Elias. Automobilismo brasileiro e mídia: desenvolvimento, popularização e imaginário esportivo. 2006. $100 \mathrm{f}$. Trabalho de conclusão de curso. (Graduação) - Curso de Graduação em Educação Física, Universidade Gama Filho, Rio de Janeiro, 2006. 
Automobilismo na cidade do Rio de Janeiro de 1954 a 1966: das ruas para o autódromo. Rio de Janeiro. 2010. 126f. Dissertação (Mestrado em Educação Física) - Programa de Pós Graduação em Educação Física da Universidade Gama Filho, Rio de Janeiro, 2010.

Recebido em: 17.08.2009

Aprovado em: 09.03.2010

Wovimento, Porto Alegre, v. 16, n. 03, p. 51-70, julho/setembro de 2010. 